\title{
Algumas reflexões acerca das jovens camponesas, agroecologia e decolonialidade
}

\author{
Some reflections on young peasants, agroecology and decoloniality
}

\author{
Nádia Luzia Balestrin ${ }^{1}$
}

\begin{abstract}
Resumo
A proposta deste estudo é trazer à tona a discussão em relação ao universo feminino rural, mais especificamente as jovens camponesas inseridas num contexto de relações patriarcais e de dominação masculina. Parte-se de alguns questionamentos: como as relações patriarcais se manifestam e quais suas consequências para as jovens camponesas? Como a agroecologia, as lutas e a participação em movimentos sociais e organizações contribuem para o empoderamento das jovens camponesas e o enfrentamento à colonialidade do poder patriarcal? As teorias decoloniais auxiliam no entendimento das relações patriarcais consideradas como reflexos da colonialidade do poder. A agroecologia, os movimentos sociais, as organizações de mulheres do campo, apresentam-se como possíveis alternativas de desconstrução das colonialidades e possibilitam o empoderamento das jovens camponesas.
\end{abstract}

Palavras-chave: Jovens camponesas. Agroecologia. Patriarcado. Decolonialidade.

\begin{abstract}
The purpose of this study is to bring to the forefront the regarding the rural feminine universe, more specifically the young peasants inserted in a context of patriarchal relations and male domination. Some questions arise: how do patriarchal relations manifest themselves and what are their consequences for young peasants? How does agroecology, struggles and participation in social movements and organizations contribute to the empowerment of young peasants and confronting the coloniality of patriarchal power? The decolonial theories help in the understanding of the patriarchal relations considered as reflections of the coloniality of the power. Agroecology, social movements, rural women's organizations are presented as possible alternatives for the deconstruction of colonialities and enable the empowerment of young peasants
\end{abstract}

Keywords: Young peasants. Agroecology. Patriarchy. Decoloniality.

\section{Introdução}

Este estudo é um ensaio teórico que tem como propósito esboçar uma reflexão sobre o tema das relações de poder patriarcal em que as jovens camponesas estão inseridas e como o seu envolvimento com a agroecologia e os movimentos sociais do campo contribuem para seu empoderamento e superação do patriarcalismo. O interesse pelo tema se deu a partir estudos que vêm sendo desenvolvidos sobre a juventude camponesa e seu projeto de vida agroecológico, tema da tese

\footnotetext{
${ }^{1}$ Doutoranda do Programa de Pós-Graduação em Sociologia da Universidade Federal do Paraná (UFPR). Integrante do Grupo de Estudos Rurais e Ambientais do Paraná (CERU) vinculado ao CNPQ. E-mail: nadiabalestrin @ gmail.com
} 
da autora. Nesse momento não se tem a pretensão de esgotar o tema. Trata-se de uma reflexão em construção.

A trajetória histórica e social do rural brasileiro mostra que um de seus pilares de sustentação foi o patriarcalismo, entendido aqui como o domínio dos homens sobre as mulheres. O modelo patriarcal colonial repercutiu na composição familiar, nas relações de trabalho, onde prevaleceu a centralidade do poder do homem estendido a outras esferas, inclusive a política. "A família patriarcal fornece assim, o grande modelo por onde hão de se calcar, na vida política, as relações entre governantes e governados, entre monarcas e súditos” (HOLANDA, 1995, p. 85). Nesta perspectiva de poder, centrada na figura "pater" cabia às mulheres o cuidado com a vida privada, com os filhos, o marido e a submissão.

O processo de colonização do Brasil teve como locus de enunciação a figura masculina. $\mathrm{O}$ europeu colonizador foi imprimindo sua marca: “Às Américas chegou o homem heterossexual /branco /patriarcal /cristão/ militar /capitalista/ europeu” (GROSFOGUEL, 2008, p.122). O paradigma eurocêntrico do sistema-mundo foi produzindo uma matriz de poder colonial que foi perpassando todas as dimensões da vida social, política e econômica. Como herança do colonialismo estas relações perduram até os dias atuais e são definidas como colonialidade do poder.

Grosfoguel (2008) define "colonialidade do poder" como um poder que perpassa variadas hierarquias globais - "heterarquias" - como forma de dominação e exploração. A expansão colonial pelo mundo "semeou" este modelo hegemônico de sistema-mundo eurocêntrico. Segundo Quijano (2005) as sociedades foram classificadas em superiores e inferiores também a partir da raça, que para o autor “ (...) converteu-se no primeiro critério fundamental para a distribuição da população mundial nos níveis, lugares e papéis na estrutura de poder da nova sociedade” (QUIJANO, 2005, p.118). Assim o modelo que vai se sobrepor aos povos colonizados é um modelo baseado em hierarquias, dicotomias e dualismos impostos pelo colonizador europeu.

Lugones (2014) aponta para a existência também de uma colonialidade do gênero. Dentre as hierarquias dicotômicas impostas pelos colonizadores, a autora afirma que está a dicotomia entre homens e mulheres, bem como a dicotomia entre os humanos e não humanos. Para romper com a colonialidade do gênero é preciso romper com o modelo universalista eurocêntrico e racista. “Descolonizar o gênero é necessariamente uma práxis. É decretar uma crítica da opressão de gênero racializada, colonial e capitalista heterosexualizada visando uma transformação vivida no social" (LUGONES, 2014, p. 940). Assim o enfrentamento ocorre por meio de um feminismo de resistência capaz de fazer o enfrentamento às variadas expressões de colonialidade, seja do poder, do saber, do ser e do gênero. 
Relacionando com o tema das jovens camponesas pode-se dizer que a questão do poder expresso pela estrutura patriarcal presente desde o início da história brasileira pode ser entendido como expressão de colonialidade do poder e de gênero que reflete uma hierarquia dicotômica entre homens e mulheres, definindo uma posição secundária para a mulher. O cenário em que se situam as jovens camponesas e na agricultura familiar tende a ser marcado pela invisibilidade e centralidade da figura masculina.

Ao mesmo tempo dando sinais de superação desta condição, abre-se outra perspectiva. As jovens camponesas, inseridas num processo de transição agroecológica, vivenciam um movimento de empoderamento e equidade fortalecido também pela participação em movimentos sociais, feministas, ecológicos, dentre outros. Parte-se da hipótese que o envolvimento com a agroecologia e a participação nos mais variados movimentos, de lutas no campo, fortalecem o processo de desconstrução da colonialidade do poder em relação ao patriarcado rural. Isso vai além da lógica produtivista capitalista e incorpora outras variáveis, dentre elas o cuidado com a natureza, com o meio ambiente, o respeito à diversidade étnica, cultural, a igualdade entre homens e mulheres, o desejo de uma sociedade mais justa, segurança alimentar etc.

\section{$O$ contexto das (os) jovens camponesas (es)}

O processo de modernização da agricultura brasileira e a industrialização produziram mudanças para o meio rural. A mecanização agrícola expulsou trabalhadores para as cidades. O uso de insumos químicos e agrotóxicos em nome da produtividade desde então, vem causando danos aos ecossistemas comprometendo a flora, a fauna e os humanos. No Brasil, duas vias agrícolas tornaramse mais visíveis, principalmente a partir dos anos 1970. Uma delas com uma agricultura baseada no latifúndio, na grande produção e agroexportadora. Outra, focada na pequena propriedade, na agricultura familiar e camponesa, que por sua vez tem um perfil heterogêneo com uma diversidade de seus atores (WANDERLEY, 2009).

O censo do 2010 (IBGE, 2011) apontou que apenas 15,6\% da população brasileira vive no meio rural. Principalmente as (os) jovens são atraídos para as cidades em busca de trabalho remunerado, de "autonomia", vida social mais dinâmica e possibilidade maior de dar continuidade aos estudos. Brumer (2007) afirma que as (os) jovens são atraídos às cidades a partir de dois fatores: de atração e de expulsão. Os fatores de expulsão são anteriores aos de atração. Dentre as variáveis de expulsão pode-se citar a falta de terra, a questão da sucessão e a falta de autonomia. Os fatores 
atrativos estão relacionados à possibilidade de ter férias, finais de semana livres, trabalhos menos penosos.

Wanderley (2007, p. 24) em um estudo desenvolvido com jovens de Pernambuco, apresenta que "a estrutura de distribuição da terra é a maior responsável pelo bloqueio à reprodução social dos pequenos agricultores camponeses (...) e em consequência provoca nos jovens a necessidade da migração". Com a propriedade de terra geralmente pequena, nem todos os filhos conseguem manterse na atividade agrícola e nem suas respectivas famílias. Resta-lhes assim a opção de migrar para as cidades.

Este cenário repete-se também com as (os) jovens integrantes do Movimento dos Trabalhadores Sem Terra (MST). Os lotes conquistados pela reforma agrária, pela sua extensão não comportam a subdivisão. Alguns migram para as cidades e outros engajam-se no movimento pela posse da terra. A prioridade governamental é para as famílias que possuem filhos e não as (os) jovens (MORISSAWA, 2001). Isso reflete as dificuldades enfrentadas pelos jovens de ambos os sexos.

Mas tratando-se das jovens camponesas, o grau de dificuldade é ainda maior pois enfrentam as questões relacionadas ao gênero. Os filhos homens geralmente são considerados mais aptos para assumir a posse e a gestão da propriedade. Segundo Paulilo (2005) o tema do acesso à posse e uso da terra na mesma proporção para homens e mulheres, se apresenta como um "tabu" não somente para as famílias, como também muitas vezes ignorado pelos próprios pesquisadores, refletindo a solidez da base patriarcal e de certa forma a sua naturalização. As jovens mesmo trabalhando arduamente tinham pouca possibilidade de posse da terra. O reconhecimento de seu trabalho muitas vezes se dava em forma de um dote, "em geral composto por roupas de cama e mesa, uma máquina de costura, uma vaca de leite ou uma porca e a festa das bodas" (PAULILO, 2005, p. 5/7).

\section{Modelo patriarcal de família: uma expressão de colonialidade do poder}

Ainda é muito presente a estrutura familiar patriarcal, em que predomina a supremacia masculina no meio rural. Para Sabbato et al. (2009) o trabalho das mulheres na roça, hortas, atividades domésticas é considerado como um auxílio para a família, uma "ajuda". A divisão sexual do trabalho, cria uma identidade em torno do trabalho doméstico destinado a reprodução social do grupo familiar. O trabalho da mulher compreendido como uma força de trabalho secundária reforça a questão da sua inferiorização e da sua subordinação na família e no trabalho. O homem é considerado o único provedor e o trabalho feminino ocupa uma posição secundária. Estas relações de poder são 
construídas e absorvidas culturalmente e tendem a repetir-se nas relações com os (as) filhos (as), dentro das famílias camponesas. "O patriarcado refere-se a milênios de história mais próxima, nos quais se implantou uma hierarquia entre homens e mulheres com primazia masculina" (SAFFIOTI, 2015, p.145).

Abramovay et al. (1998) em estudo desenvolvido com famílias de agricultores familiares do município de Saudades em Santa Catarina, identificaram que em relação à questão sucessória da transmissão da posse da terra geralmente se destina a um dos filhos homens. As filhas tendem a ficar fora deste processo. É a figura paterna que define o momento de fazer o processo sucessório, a passagem das responsabilidades da propriedade rural geralmente para um sucessor masculino. Tem ocorrido uma "masculinização" do meio rural. Ocorre uma migração seletiva que não está relacionada somente aos atrativos do mercado de trabalho urbano que atrai mais as moças do que os rapazes. Há uma "exclusão" das jovens nos processos sucessórios da propriedade onde lhes é concedida a sucessão somente quando a família não possui filhos homens.

Percebe-se que são relações de poder que estão em jogo, em que predomina a figura masculina. Os próprios pais preferem que seus filhos homens fiquem morando no campo do que as filhas, pois consideram que estão melhor preparados para gerir a propriedade. Assim "o processo sucessório, e de certa forma toda a organização do processo de trabalho, são enviesados contra a mulher" (ABRAMOVAY et al. 1998, p. 74). A forma como o poder se distribui na família não deixa de ser um fator impulsionador de migração das jovens, pois são invisíveis tanto para a sucessão como nas atividades desenvolvidas, geralmente domésticas. Como afirma Panzutti (1996, p. 9): “o desempenho da mulher na produção familiar não é reconhecido socialmente porque o espaço ‘público' continua sendo domínio masculino”. A esfera pública é um espaço em que ainda predomina a ideia de que é destinado aos homens.

Silvestro et al (2001) afirmam em uma pesquisa realizada no oeste de Santa Catarina que ocorre a não participação das moças nas tomadas de decisão no interior da unidade familiar. Para os autores a não participação das moças significa o seu pouco interesse e afastamento das atividades agrícolas. Mas porque ocorre esse pouco interesse? As jovens estariam pouco afinadas com as atividades com a terra? Os autores, contudo, reconhecem, que em muitas propriedades "o pai controla todas as atividades e todos trabalham em todas as atividades" em outras "o pai controla todas as atividades e o trabalho é dividido" (SILVESTRO et al. 2001, p.78,79). A centralidade do poder paterno afeta tanto os filhos homens como as filhas mulheres. Eles possuem uma autonomia muito limitada, pouco espaço para iniciativas próprias, conta bancária, etc. Mas a carência de autonomia é 
muito mais acentuada para com as filhas, que inclusive são privadas de assumir a gestão e a posse da propriedade.

A migração das jovens para as cidades tem afetado também a composição de novas unidades familiares e produtivas (ABRAMOVAY et al. 1998). Os "papeis" tradicionalmente construídos às jovens, de mãe e esposa, vem dando espaço para outros projetos pessoais fora da agricultura. Isso repercute nos casamentos dos jovens homens que permanecem no campo. Este cenário tem se apresentado também em outras partes do mundo, como é o caso da França, onde o número de mulheres que migraram do campo para as cidades tem sido maior do que a dos homens. Nesse contexto o casamento com um camponês tem se tornado praticamente impossível. Bourdieu, na obra "O Camponês e o Corpo" cita:

[...] é normal que a jovem camponesa associe à vida urbana certos tipos de roupas e de penteados, signos manifestos, a seus olhos, de libertação. Em resumo, ela não vê senão, como se diz, o lado bom da cidade $\{. .$.$\} Em virtude da dualidade dos quadros$ de referência, consequência da diferente penetração dos modelos culturais urbanos em ambos os sexos, as mulheres julgam seus conterrâneos camponeses segundo critérios que não lhes dão nenhuma chance (BOURDIEU, 2006, p .89).

Mas o que significa a sua ida à cidade? Numa matriz familiar patriarcal, sua ida à cidade significa a conquista de sua "carta de alforria", sua liberdade e independência. É a possibilidade de desvencilhar-se de uma realidade de invisibilidade, inferioridade e pouca autonomia. Stropasolas (2006) afirma que com mais chances de dar continuidade aos estudos as jovens vão protelando para mais tarde o casamento. Com escolaridade maior, dificilmente retornam para o campo ou contraem casamento com um jovem agricultor. O estudo acaba sendo uma qualificação para o trabalho urbano. Entre as moças há uma visão mais negativa em relação à sua permanência no campo, ou seja, o seu projeto de vida está mais voltado à vida urbana do que a do meio rural.

Este cenário apresentado reflete os estudos feitos com famílias de agricultores familiares do sul do Brasil pelos autores mencionados. Contudo, não significa dizer que dão conta de explorar toda a realidade dos (as) jovens do campo, que por sua vez é marcado pela heterogeneidade. Ao mesmo tempo em que ainda se manifesta a presença de uma estrutura patriarcal, há também toda uma dinâmica de participação, de emancipação e empoderamento das mulheres e jovens no campo, que se organizam em movimentos de luta a fim de ir aos poucos desconstruindo tal lógica. 
Agroecologia e o protagonismo feminino: desconstruindo colonialidades (!?)

O modelo agrícola da revolução verde passou a intensificar a produtividade e a modernização do campo com o desenvolvimento de um modelo de agricultura totalmente dependente de agrotóxicos e de insumos químicos. O uso constante e intenso destes produtos vem afetando o meio ambiente, com consequências para a fauna, os polinizadores, desestabilizando os ecossistemas, contaminando a água dos rios, lagos, e lençóis freáticos. Também são constatados danos sociais em relação à saúde, como envenenamentos e doenças associadas, decorrentes do uso de agrotóxicos (GUIVANT, 1998).

Este modelo agrícola passou a ser questionado diante de tantos malefícios causados ao meio ambiente e ao próprio homem. Nos anos 1960 e 1970, houve um interesse maior em aplicar a ecologia à agricultura. Estudos e pesquisas passaram a ser desenvolvidos nesta área. Assim a agroecologia foi se constituindo numa prática resultante da aproximação de dois campos científicos: a ecologia e a agronomia. Nas décadas posteriores contribuiu para dar consistência ao conceito de sustentabilidade na agricultura (GLIESSMAN, 2000).

Atualmente costuma-se dizer que existem "agroecologias", pois ocorrem diferentes modos de concepção da mesma. Dentre as concepções existentes podemos mencionar duas delas: uma que se apresenta alavancada numa dinâmica mais tecnicista onde emerge fundamentalmente $o$ questionamento ao modelo agrícola convencional e industrial de agricultura, apontando para novas práticas sustentáveis. Outra com um caráter mais político, de movimento social em que os atores também estão envolvidos com questões como segurança alimentar, economia solidária, equidade entre gêneros, indo além da questão técnica e ambiental (ALTIERI, 2012).

Assim a agroecologia passou a ser considerada como uma possibilidade de consolidação de uma agricultura ecológica e também com um caráter de transformação social. "Trata-se de uma nova abordagem que integra os princípios agronômicos, ecológicos e socioeconômicos, à compreensão e avaliação do efeito das tecnologias sobre os sistemas agrícolas e a sociedade como um todo" (ALTIERI, 2000: p.16). Remete a uma perspectiva agrícola holística, que vai muito além do aspecto produtivista e economicista da agricultura convencional e do agronegócio.

A dinâmica da agroecologia, além de adotar práticas que minimizam os danos aos humanos e à natureza, privilegia e resgata a sabedoria e o conhecimento dos atores envolvidos: homens $\mathrm{e}$ mulheres que culturalmente estão ligados à terra, à natureza. O resgate destes conhecimentos permite entrar na seara dos saberes ignorados e silenciados ao longo da ciência moderna e seu paradigma científico dominante. Possibilita um outro olhar em relação aos saberes dos atores envolvidos como as comunidades tradicionais e camponesas, dentre outros. Boaventura Souza Santos, sociólogo 
português faz menção à diversidade de saberes que o paradigma dominante da ciência moderna ignorou. Fala da "Ecologia de Saberes":

A ecologia de saberes é um conjunto de epistemologias que partem da possibilidade da diversidade e da globalização contra-hegemônicas e pretendem contribuir para as credibilizar e fortalecer. $\{\ldots\}$ A ecologia de saberes parte do pressuposto que todas as práticas de relação entre seres humanos e entre eles e a natureza participa mais de uma forma de saber, e portanto, de ignorância (SANTOS, 2010, 156-157).

A "ecologia de saberes" tem um caráter contra-hegemônico, no sentido da acolhida dos saberes provenientes de diversos atores, dispersos nos mais variados cenários conectados às suas origens, práticas e cultura. Distingue-se assim do conhecimento totalitário da racionalidade científica moderna e homogeneizadora. A "ecologia de saberes" trilha outro caminho que por sua vez vai deixando ecoar outras vozes silenciadas pela herança dos processos de colonização eurocêntrica que se alastrou pelo mundo.

Neste sentido é que situamos a agroecologia como uma alternativa que possibilita criar condições favoráveis às vozes silenciadas principalmente das mulheres e das jovens camponesas. É sabido que a condição da mulher durante um período muito longo da história ficou relegada à exclusão, como afirma Bourdieu (2016, p.135)

Excluídas do universo das coisas sérias, dos assuntos públicos e mais especificamente dos econômicos (...) ficaram durante muito tempo confinadas ao universo doméstico e às atividades associadas à reprodução biológica e social da descendência.

A trajetória de empoderamento da mulher foi se fortalecendo principalmente a partir do século XX. O Movimento Feminista, nas mais variadas expressões, com as discussões de gênero, foi impulsionando inserções e movimentos também no campo. As mulheres foram conquistando espaços e direitos e fazendo o enfrentamento da estrutura patriarcal em todas as instâncias.

As mulheres da Via Campesina Brasil, por exemplo, têm uma trajetória de lutas na construção de um projeto popular de agricultura camponesa feminista, tendo por base os princípios da agroecologia, da cooperação e da soberania alimentar. Para Schwendler (2017) as mulheres da Via Campesina têm se manifestado como grandes defensoras de um modelo agrícola sustentável e voltado para a questão da soberana alimentar. Também se colocam favoráveis a um projeto de sociedade pautado pela igualdade entre homens e mulheres, onde o patriarcado, as relações capitalistas, os preconceitos raciais e étnicos e a violência contra a mulher deixem de existir.

Neste contexto a agroecologia vem sendo uma das bandeiras de luta para as mulheres pela sua dinâmica política, social, econômica e ecológica. Além disso, aquelas atividades desenvolvidas 
pelas mulheres no dia a dia, na agricultura convencional, despercebidas e minimizadas, ganham relevância na agroecologia. Ema Siliprandi (2015) em sua tese de doutorado "Mulheres e Agroecologia" realizada na Universidade de Brasília, apresenta experiências de agroecologia com mulheres e jovens de todas as regiões do Brasil e constata que:

A agroecologia valoriza as atividades tradicionalmente desenvolvidas pelas mulheres dentro do sistema de produção familiar (hortas, pomares, pequenos animais, transformação caseira de produtos) envolvendo-se necessariamente em várias etapas do processo produtivo (SILIPRANDI, 2015, p.105).

Assim, a participação das mulheres nas lutas sociais e no desenvolvimento da agroecologia como uma nova prática agrícola, tem favorecido as mulheres em relação à sua autonomia e poder de decisão (PACHECO, 2005). As experiências agroecológicas desta forma podem contribuir para a ampliação dos espaços de atuação da mulher e reforçar o protagonismo feminino nesta nova agricultura.

A experiência tem mostrado, no entanto, que a participação em processo de transição para a agroecologia, ao introduzir elementos que potencialmente desestabilizam a lógica patriarcal, pode abrir espaço para a mudança de padrões de gênero, criando brechas para o reconhecimento de alternativas de vida às mulheres, para além dos papéis tradicionais. Mas para quebrar esta lógica é preciso que haja um processo de "empoderamento" também político dessas mulheres, o que vai depender basicamente, de que elas consigam aparecer (individual e coletivamente) como sujeitos ativos, nas famílias, nas comunidades, até influenciarem nas instituições públicas, nas políticas, na sociedade. Enfim, que as mulheres se façam reconhecer e sejam reconhecidas" (SILIPRANDI, 2015, p.108).

Siliprandi (2015) em sua coleta de dados tem mostrado com muita clareza como a agroecologia, nos mais variados contextos brasileiros em que estão inseridas as mulheres, se apresenta como algo emancipatório. Remete principalmente ao reposicionamento das mulheres como partícipes de um processo, de uma nova perspectiva de agricultura, de visibilidade e gestão familiar. Neste processo de transição agroecológica as experiências relatadas em sua pesquisa empírica onde as mulheres são protagonistas, ecoa também para as jovens. Elas visualizam a possibilidade inclusive de participar do Programa do governo federal "Minha primeira terra" destinada aos jovens e adquirir seu pedaço de terra, ficar no campo e gerir a propriedade, ao invés de somente ser colaboradora dos parceiros com sua mão de obra. O envolvimento com a agroecologia tem reforçado o entendimento que as atividades domésticas não dizem respeito somente às mulheres, mas também aos homens e portanto, precisam ser compartilhadas. Sinaliza também a necessidade de investir na educação e 
possibilitar aos jovens o contato com a possibilidade de ficar no campo e apostar num modelo de agricultura sustentável.

Outro aspecto importante que vale ressaltar diz respeito às formas de organização que tanto as mulheres como as jovens participam. Seja em movimentos sociais, associações, sindicatos, pastorais, dentre outros. Isso fortalece não só na transição para a agroecologia, como no processo de superação da forte estrutura patriarcal ainda presente na sociedade, seja na esfera pública ou privada. Com o esforço de superação das amarras da colonialidade do patriarcado as mulheres, as jovens, sentem-se mais seguras para tomar as rédeas de suas vidas, de seus projetos e conseguem enfrentar os desafios da velha estrutura que ainda persiste.

Essas mulheres estão mostrando, com sua ação, que é possível resistir, denunciar, organizar-se, construindo-se como sujeitos políticos, que a partir de suas múltiplas identidades, não se conformam com o destino 'injusto e amargo' reservado a elas no patriarcado (SILIPRANDI, 2016, p. 338).

Compreendendo a agroecologia como um movimento político, social e ecológico os atores envolvidos neste processo são desafiados a mudar suas representações não só referente ao modelo agrícola e da natureza, mas também das relações de poder em suas famílias e na sociedade, do direito aos territórios, dentre outros aspectos. Pode-se dizer que as mulheres jovens camponesas agroecológicas sentem-se mais fortalecidas no processo de ruptura com os padrões de colonialidade do poder patriarcal que foram sendo sedimentados no percurso histórico do Brasil.

\section{Considerações finais}

Os fundamentos de uma sociedade que tem como uma das matrizes o patriarcado consequentemente produz relações desiguais entre homens e mulheres, em que o poder de um se sobrepõe ao do outro. Decorre daí a classificação, a inferiorização, a violência, a desigualdade salarial, invisibilidade, que atinge as jovens e mulheres tanto no rural quanto no urbano. Os estudos aqui apresentados refletem dentre outros fatores que as relações familiares patriarcais contribuem para o processo migratório das jovens camponesas e em algumas circunstancias dos jovens também. Mas apontam também um movimento que caminha na tentativa de desconstrução da dominação patriarcal. Novos atores frutos de organizações e movimentos sociais do campo com muita luta resistem, se reinventam e vão minando as bases das colonialidades ainda existentes. 
A agroecologia na sua dimensão política, vem provocando a construção de relações mais equitativas entre homens e mulheres, como um processo, que possibilita o reconhecimento do protagonismo feminino. As mulheres da Via Campesina que tem como bandeira de luta a construção de um outro projeto de sociedade e de agricultura, são exemplo disso, dentre outros grupos organizados. São experiências que confirmam o empoderamento da mulher e abrem caminhos para desconstruir a colonialidade do poder patriarcal. Contudo não significa dizer que as relações patriarcais foram superadas. Há um longo caminho a percorrer. A perspectiva do pensamento decolonial possibilita olhar a realidade social com epistemologias próprias. Desafia a produção do conhecimento e alternativas que possam contribuir para a libertação das imposições e dicotomias deixadas pela colonialidade do poder, do saber e de gênero e emancipar os atores envolvidos.

\section{Referências}

ABRAMOVAY, A. (Coord) SILVESTRO, N. C; BALDISSERA, I.T.; FERRARI, D.; TESTA, V.M. Juventude e Agricultura Familiar - Desafios dos Novos Padrões Sucessórios. Brasília: UNESCO, 1998.

ALTIERI, M. Agroecologia: a Dinâmica Produtiva da Agricultura Sustentável. Porto Alegre: Editora Universidade/UFRGS.

Agroecologia: Bases Científicas para uma Agricultura Sustentável. 3 ed. São Paulo Rio de Janeiro: Expressão Popular - AS-PTA, 2012.

BOURDIEU, P. O Camponês e seu Corpo IN. Revista de Sociologia e Política No 26: 83-92. JUN. 2006.

A Dominação Masculina - A Condição Feminina e a Violência Simbólica. $3^{\mathrm{a}}$ edição, Rio de Janeiro: BestBolso, 2016.

BRUMER, A. A problemática dos Jovens na Pós-Modernidade. IN: CARNEIRO M. J. ; CASTRO, E. G. Juventude Rural em Perspectiva. Rio de Janeiro: Mauad X, 2007.

GLIESSMAN, S. Agroecologia - Processos Ecológicos em Agricultura Sustentável. Porto Alegre: Editora Universidade/UFRGS, 2000.

GUIVANT, J, S. A agricultura sustentável na perspectiva das Ciências Sociais. IN: VIOLA, E. J. et al. Meio Ambiente, Desenvolvimento e Cidadania: desafios para as Ciências Sociais. São Paulo: Cortez; Florianópolis, Universidade Federal de Santa Catarina, 1998.

GROSFOGUEL, R. Para descolonizar os estudos de economia política e os estudos pós-coloniais: Transmodernidade, pensamento de fronteira e colonialidade global. Revista Crítica de Ciências Sociais, 8-, Março, 2008: 115-147. 
HOLANDA, S.B. Raízes do Brasil. 26 ed. São Paulo: Companhia das Letras, 1995.

IBGE. Instituto Brasileiro de Geografia e Estatistica. Censo Demográfico 2010. Características da população e dos domicílios Resultados do universo. Disponível:http://www.ibge.gov.br/home/estatistica/populacao/populacao_jovem_brasil Acesso em: 03 Out. 2016.

LUGONES, M. Rumo a um feminismo descolonial. Estudos Feministas, Florianópolis, v. 22, n. 3, p. 935-952, set./dez, 2014.

MORISSAWA, M. A História da Luta pela Terra e o MST. São Paulo: Expressão Popular, 2001.

PACHECO, M.E L. Construindo um Diálogo: Feminismo e Agroecologia (entrevista). Revista Proposta, Rio de Janeiro, ano 28/29, nº 103/104, dez/mar, 2005.

PANZUTTI, N. P. M. Mulher rural: eminência oculta. Informações Econômicas, São Paulo, v.26, n.3, p.9-22, 1996.

PAULILO, M.I. Trabalho doméstico: reflexões a partir de Polany e Arendt. In: Serviço Social em Revista. (2005). Disponível em www.uel.br/revistas/ssrevista/c-v8n1_ignez.htm. Acesso em 04.jun.2019.

QUIJANO, A. Colonialidade do poder, eurocentrismo e América Latina. In: LANDER, E. (Org.). A colonialidade do saber: eurocentrismo e ciências sociais. Perspectivas latino-americanas. Colección Sur Sur, CLACSO, Ciudad Autónoma de Buenos Aires, Argentina. Set. 2005.

SABBATO, A; MELO, H.P; LOMBARDI, M. R; FARIA, N. Estatísticas Rurais e Economia Feminista - Um Olhar sobre o Trabalho das Mulheres. Brasilia: MDA, 2009.

SAFFIOTI, H. Gênero, Patriarcado e Violência. São Paulo: Expressão Popular, 2015.

SANTOS, B, S. A Gramática do Tempo - para uma nova cultura política. São Paulo: Cortez, 2010.

SCHWENDLER, S. Feminismo camponês e popular: práticas, saberes e discursos de gênero, construídos nas conexões sociais e políticas dos movimentos sociais de campo. IN: TAMANINI, M, Boschilia, R. SCHWENDLER S. F. (orgs.) Teorias e Políticas de Gênero na Contemporaneidade. Curitiba: Editora UFPR, 2017.

SILIPRANDI, E. Mulheres e Agroecologia - Transformando o Campo, as Florestas e as Pessoas. Rio de Janeiro: Editora UFRJ, 2015.

SILVESTRO, M.S.; ABRAMOVAY, R. (Coord.); MELLO M.A. DORIGON, C.; BALDISSERA, I.T. Os Impasses da Sucessão Hereditária na Agricultura Familiar. Epagri; Brasília: Nead/Ministério do Desenvolvimento Agrário, 2001.

STROPASOlAS, V.L. O Mundo Rural no Horizonte dos Jovens. Florianópolis: Ed. da UFSC, 2006. 
WANDERLEY, M, N, B. Jovens Rurais de Pequenos Municípios de Pernambuco: que Sonhos para o Futuro. IN: CARNEIRO M.J.; CASTRO, E.G. Juventude Rural em Perspectiva. Rio de Janeiro: Mauad X, 2007.

O Mundo rural como Espaço de Vida - Reflexões sobre a propriedade da terra, agricultura familiar e ruralidade. Porto Alegre: Editora da UFRGS, 2009.

Artigo recebido em 30/03/2019. Aceito para publicação em 26/06/2019. 